\title{
Towards a Culturally Appropriate Mental Health System: Sudanese-Australians' Experiences with Trauma
}

\author{
Alicia Copping \\ University of Tasmania, Australia
}

Jane Shakespeare-Finch

Queensland University of Technology, Australia

Douglas Paton

University of Tasmania, Australia

\begin{abstract}
A ustralia is fortunate to welcome approximately 13,000 humanitarian entrants per year, most of whom have experienced protracted violence, hardship and life in refugee camps. The majority of humanitarian migrants were raised in cultural contexts very different to that of Australia, contributing to the increasing diversity of this region. With this diversity comes a responsibility to ensure every Australian receives culturally appropriate mental healthcare. Those who are forced into migration have experienced trauma and the stress of acculturation often compounds this trauma. This study investigated the experience of trauma from the perspectives of Sudanese-Australians. Grounded theory methodology was employed to extract themes from interviews with 15 Sudanese-Australians aged between 19 and 49 years. Results demonstrated four overarching themes: support, religion, strength and new possibilities. The data within these themes are compared and contrasted with previous literature that has examined notions of trauma, distress and growth in western populations. Conclusions drawn from these results highlight the need to build inclusive practices that support diversity into existing trauma services in Australia.
\end{abstract}

Keywords: trauma, posttraumatic growth, refugee mental health, culture, humanitarian

\begin{abstract}
A 16 year old girl is walking home from school. Suddenly she is attacked by a group of four older men. The men drag her into a nearby house where she is systematically raped and assaulted. She escapes 12 hours later. The memory of that event never leaves her, but somehow she has managed to rebuild her life. She has made her way along the post life crisis journey to a point where, though she can never forget what has happened to her, she has survived.
\end{abstract}

The above scenario is culturally neutral. It could happen in any country, any city, to anyone. How the survivor of trauma reacts to such an event, the meaning she attributes to it, the way she thinks about it, who she chooses to tell, if anyone, and how she expects them to react to the knowledge, what resources she draws on to adapt to the crisis and many other nuances of an experience like this, are all related to the cultural values and norms a person holds. The aim of this article is to highlight the importance of building culturally appropriate practices (i.e., those designed to foster constructive therapeutic interactions between representatives of different cultures) into trauma support services in Australia, particularly for forced migrants.

\section{Trauma}

Trauma in western psychology is defined as 'actual or threatened death or serious injury, or other threat to one's physical integrity' (American Psychiatric Association [APA], 2000, p. 467). This definition is set in a diagnostic framework and therefore involves the event being coupled with feelings of fear, helplessness and/or horror. Janoff-Bulman (1992) suggested that a traumatic 
experience is one that shatters the fundamental assumptions a person holds about the self, others and the world. Traditionally, western psychology has focused on the negative outcomes of experiencing such an event (e.g., post-traumatic stress disorder); however, research is increasingly demonstrating that people do not always experience adverse outcomes alone. Many survivors of traumatic events are resilient and others report benefits emanating from the experience. Arguably, the most comprehensive model of positive posttrauma adaptation is Tedeschi and Calhoun's $(1995,2004)$ cognitive model of posttraumatic growth (PTG).

PTG is defined as 'significant beneficial change in cognitive and emotional life, beyond previous levels of adaptation, psychological functioning, or life awareness' (Tedeschi \& Calhoun, 2003, p. 1). This model of growth asserts that an adverse event large enough to shatter existing schemas provides a catalyst for growth. The survivor's subsequent change in cognitions, emotions and behaviour develop as a result of engaging in the struggle to synthesise the traumatic experience into life posttrauma, a process known as effortful rumination (Calhoun \& Tedeschi, 2006). PTG refers to both the process by which an individual may develop positive posttrauma outcomes and the outcomes of growth itself (McMillen, 1999; Tedeschi \& Calhoun, 2004). Calhoun and Tedeschi's (2006) model of PTG does not assume that growth is an automatic by-product of experiencing trauma, or that it occurs for all people, and further asserts that growth can be experienced in conjunction with ongoing distress and is often accompanied by wisdom.

PTG outcomes identified in U.S. samples include: increased perceptions of personal strength, appreciation of life, and new possibilities; stronger and more fruitful relationships with others; and positive spiritual and religious change. These outcomes can be measured using the Posttraumatic Growth Inventory (PTGI; Tedeschi \& Calhoun, 1996). Calhoun and Tedeschi (2006) have recently added the notion of sociocultural influences in their model of PTG to encompass both proximate and distal influences. Proximate culture refers to an individual's primary reference groups (e.g., friends, family, community), while distal culture refers to the outer society. These distal variables can include religion, and culturally sanctioned norms and values (see Hofstede's extensive literature that includes individualism/collectivism, uncertainty avoidance, power distance, masculinity/femininity).

A catalyst for Calhoun and Tedeschi's (2006) inclusion of sociocultural influences was the differences found in the manifestations of growth across cultures when utilising quantitative methodology (e.g, Ho, Chan, \& Ho, 2004; Peltzer, 2000; Znoj, 2005). Subtle differences in the construction of PTG in Australia have also been found quantitatively (e.g., Morris, Shakespeare-Finch, Rieck, \& Newberry, 2005) and qualitatively, with increasing emphasis placed on compassion, and little emphasis on religious or spiritual growth (Shakespeare-Finch \& Copping, 2006; Copping, Shakespeare-Finch \& Paton, 2008). These differences suggest that the influence of culture on the experience of life crises is an important factor to consider, particularly for host nations providing trauma support for humanitarian entrants.

\section{Trauma in Refugee Populations}

The traumatic experiences of forced migrants from Sudan are many, and there are also significant challenges in their flight from their home and in their resettlement in Australia that serve to compound distress (Oktikpi \& Aymer, 2003). Distress outcomes of the traumatic experience that are often stated to be specific or particularly pertinent to the refugee experience include: disruption to relationships with friends, family, religious networks and cultural systems; anxiety and helplessness; grief and depression; loss of trust and altered view of the future (Halcon, et al., 2004; Jaranson et al., 2004; Murray, Davidson, \& Schweitzer, 2008). It has been suggested that all forced migrants experience some degree of PTSD symptomatology (Roncevic-Grzeta, Franciskovic, Moro, \& Kastelan, 2001); however, the prevalence varies greatly between different cohorts, appears to be dose-dependent, and may occur in a curvilinear pattern across the resettlement experience (Murray et al., 2008). Further, the diagnosis of PTSD in people from cultures outside industrialised nations may be flawed, as the understanding and expression of trauma may differ across culture.

For example, a study by Schweitzer, Melville, Steel, and Lacherez (2006) of Sudanese humanitarian entrants in Australia found that while 13\% met all three diagnostic criteria for PTSD, the majority of the entire sample met the re-experiencing criterion, and $71 \%$ stated they had deliberately avoided recollections of their experiences. Interestingly, these avoidance coping measures are often seen as adaptive in Sudanese culture, and contribute to less subjective psychological distress despite often contributing to a diagnosis of PTSD when based in western psychological practice (Halcon et al., 2004; Schweitzer, Greenslade, \& Kagee, 2007).

Though the prevalence rates for PTSD in former refugee samples are relatively higher than the Australian mainstream, the numbers are clearly well below $100 \%$, suggesting that a majority of former refugees are resilient (Schweitzer et al., 2006). Support from family, their own community and religion are often seen as vital to the survival and successful adaptation of African refugee samples (Goodman, 2004; Halcon et al., 2004, Schweitzer et al., 2006; Schweitzer et al., 2007; Tilbury \& Rapley, 2004). Whether refugee populations experience PTG is yet to be uncovered.

\section{Rationale and Aims}

Cultural competence refers to a system of behaviours, attitudes and skills that a practitioner may employ within any 
workplace that fosters cultural appropriateness, the integration of value for diversity and an understanding of the influence of culture on oneself as a mental healthcare provider as well as on one's clients (National Health and Medical Research Council [NHMRC], 2005; Ethnic Communities' Council of Victoria [ECCV], 2006). It is therefore necessary for services that are used within culturally and linguistically diverse (CALD) communities to be evidence-based, in order to inform culturally appropriate practices that may otherwise apply inappropriate social, psychological and therapeutic assumptions to culturally diverse populations.

In order to understand how to provide culturally appropriate trauma support services we must first understand how the experience of trauma is conceptualised by different cultural groups and what existing models of care they use. Simply using an established western model of trauma and counselling ignores the ethical and political obligations professionals have to provide empirically supported, culturally competent practices to clients. Therefore, the aim of this study was to provide a rich understanding of the cultural influences that play a role in the experience and outcomes of life crises in forced migrants from Sudan.

\section{Method \\ Design}

Grounded theory (GT) was selected as the most appropriate methodology for this study. GT is a well established means of collecting and analysing qualitative data. Its primary function is to systematically generate theory based on a ground-up analysis procedure (Glaser \& Strauss, 1967). Analysis is by constant comparison (Blaikie, 2000). Initially, transcripts are coded via open coding. However, over time coding becomes more structured, with connections between codes being formed and higher order themes becoming apparent. The increasing levels of coding are referred to as axial and selective coding (see Glaser \& Strauss; Strauss, 1987; Strauss \& Corbin, 1998).

\section{Participants}

Fifteen Sudanese-Australian people (seven female and eight male) participated in the study. All participants expressed an affiliation with Christianity; however, one participant stated that he had 'converted' from an indigenous religion. Participants ranged in age from 19 to 49 years $(M=32.67, S D=8.54)$. Thirteen participants were enrolled in an educational facility such as Technical and Further Education (TAFE) or university; however, of those who stated they were enrolled in TAFE, many were studying Adult Migrant English Services alone and were otherwise unemployed. The two remaining participants were employed. All participants resettled in Australia as humanitarian entrants after spending various amounts of time in a third country, such as
Uganda, Kenya, and Egypt. All had resided in Australia for between 3 months and 5 years. This research was undertaken at the University of Tasmania, and all participants were currently living in Launceston, Tasmania (i.e., a regional setting). All interviews were conducted in English.

Participants were recruited initially through the Migrant Resource Centre of Northern Tasmania (MRC) and the University of Tasmania $(n=5)$. Ten participants were then recruited through the snowball method. Participants were informed of the study through contacts at the MRC and the university, and subsequently participants themselves, who were furnished with information sheets and brochures and had previously been briefed as to the nature of the study. Individual participants were contacted with their permission by telephone. Participants were briefed as to the nature of the study in an initial face-to-face meeting, and then invited to participate in an interview at a later date. All names appearing in this article are self-selected pseudonyms, ensuring the anonymity of participants. Ethical clearance was given by the Tasmania Social Sciences Human Research Ethics Committee, and ethical procedure was informed by extensive literature review and consultation with community leaders prior to the commencement of the research.

\section{Procedure}

Utilising a narrative, episodic interview style, all participants were asked to convey their stories in their own words. This interview procedure is based on individuals' own understandings of their experience and their expression of their story in their own words, without a structured interview schedule. Broad topics of discussion were addressed, including what participants perceived as being distressing, the feelings participants experienced at the time of these occurrences, how they coped with the events, the nature of social support and how they felt they had changed because of the events, if at all. However, these topics were not addressed as an interview schedule but were used as general areas of interest for the interviewer to probe should they be expressed by the participant.

Interviews were recorded on a digital recorder and then immediately saved in a password-protected computer file and deleted from the recorder. Interviews were then transcribed verbatim by the researcher. The transcripts were analysed by the primary author with strict adherence to grounded theory procedures outlined above utilising the NVivo $8^{\circledR}$ program.

\section{Results}

Results reported here focus on the strengths that the participants drew upon in their experiences with life crises. Comparisons are made between themes elicited from this sample and those from previous research by the authors that investigated PTG in a Caucasian-Australian sample (Copping, Shakespeare-Finch, \& Paton, 2008; 
Shakespeare-Finch \& Copping, 2006). The four main themes elicited from the current sample are discussed below. These themes were Support, Religion, Strength, and New Possibilities.

\section{Support}

One of the most substantial factors contributing to the adaptation of Sudanese-Australian participants was the support that they both give and receive. In their model of post life crisis adaptation, Copping et al. (2008) show that many of the Caucasian-Australian participants felt that their friends and family did not want to talk about their experience and, more generally, people did not understand what they had been through. Neither of these facets was articulated by Sudanese-Australian participants who expressed that a great deal of time was spent sharing their feelings with their friends. For example, Yei stated:

I do talk about it, yeah if anything happen, like when I'm talking to my friend the first thing I will start with an event that happen, they will talk about it ... then it will just disappear, maybe they will start another topic.

However, this self-disclosure occurred only at times at which negative feelings were induced by intrusive rumination or flashbacks, rather than in a more general sharing context. That is, self-disclosure was strictly a form of distress management, used to ameliorate distress experienced at that time.

Friends, family and elders were also important for support in the form of giving advice. For example, Bibo said, 'A friend is very important, that's why it's good to choose a friend who can give, who may share almost similar things because you will benefit from it'.

As Bibo mentions in the above quotation, sharing stories about similar events they had been through was one beneficial aspect of friendship and consultation with Elders. He commented further on this concept:

In our tradition, when I hear somebody has this, this, this, this, I know in my mind if I were in that position how I would do it ... I might have a story which relates to almost similar thing, I will always tell the person.

Many participants commented on the difference between the counselling paradigm in Australia and the one they are used to, specifically in advice-seeking. For many, it was important to receive specific advice in order to feel that they were 'going the right way' (Yei). An example of the need to be advised in situations of crisis was highlighted by Kasara, who stated, 'Social work here is just listen to people, you don't advices, just talk, you help them to help themselves, they have to take decision for themself, but in Africa they try to tell them decisions'.

Another important aspect of support was that through their experiences Sudanese-Australian participants felt they 'stand together'. For example, 'In Africa the most important thing we like each other like one big family, even if the war enter and you are alone but your neighbours and your friends they will not allow you to suffer by yourself' (Orange).

\section{Religion}

Perhaps the most striking difference between the Caucasian-Australian and Sudanese-Australian experience of life crises is the use of religious or spiritual coping and meaning-making. Shakespeare-Finch and Copping (2006) suggested that there was little evidence of posttraumatic growth of a religious or spiritual nature in their model elicited with a Caucasian-Australian sample. It was also the case that a Caucasian-Australian sample did not use religion as a means of coping with, or making meaning out of the experience (Copping et al., 2008). This is in stark contrast to the articulation of religious belief in the Sudanese-Australian sample. For example, Juwa described her faith in God and how this helped her through her experiences: 'If something is happen for you, you have to first believe your God, put the God first because if you just believe now God, God will be there'.

This was echoed by Luku Luku and Hope: 'But of course I just appreciate that God managed to protect me through all these challenges' (Luku Luku); 'One day God will hear, God will not always abandon his people, he will do something for them' (Hope).

Coupled with this specific faith in God and the power of prayer is a more general sense of fatalism for the Sudanese-Australian sample. For example, Yei stated: 'Everything has its time, maybe it's not my time so I have to be patient. You always get what you deserve'.

\section{Strength}

Whereas western samples are likely to see themselves as being stronger because of what they experienced (Copping et al., 2008; Shakespeare-Finch \& Copping, 2006; Tedeschi \& Calhoun, 1996), this SudaneseAustralian sample cited strength, hope and determination as reasons for their survival, that is, they are coping mechanisms for this sample rather than growth outcomes. The quotations displayed in Table 1 highlight how this theme was elicited from the data.

\section{New Possibilities}

The final overarching theme that related to growth in this Sudanese-Australian sample was a sense of new possibilities, one of the five PTG factors identified by Calhoun and Tedeschi (2006). It is impossible to separate the experience of forced migration from the resettlement (acculturation) experience, and hence it is unclear whether the focus on starting a new life and taking advantage of new opportunities is PTG, or is related to being taken out of an environment where these opportunities did not come readily. For example, James stated: 
Table 1

Quotations that exemplify Strength in the Sudanese Australian Sample

\begin{tabular}{ll} 
Facet & Quotation \\
\hline Hope and Determination & 'This is actually what gives me hope and what makes me overcome things, not giving up, because if you \\
& give up it means you are defeated, there's nothing else'. (Bibo) \\
'So that's what I managed to do with the hope that I put forward and determination and I'm now here ... \\
what I know is if you are determined on something you can make it happen'. (Kasara) \\
'Because the spirit was there ... to be determined and do something with myself ... I say I'm suffering, \\
but I'm suffering positively ... I've not lost the focus, I haven't lost my determination and I'm not going \\
to give up'. (Luku Luku) \\
'You have that hope, that strength .... that you are a man nothing can defeat you'. (Bibo) \\
'I am strong for myself, I know why I've come here'. (Gale) \\
'I thought no I have to be strong I have to do everything for myself, I have to work hard, I have to achieve \\
Something, I said I must I must look for ways in order to better myself'. (Mr Nice)
\end{tabular}

My education gives me another focus ... just forget about the way that, before, and see the new future for myself ... I will say just to concentrate on my study to hope for the new future one day. Start a new life.

Focusing on these new possibilities was important for many participants in this sample, as they were able to move on from their past experiences and think about having a better future. Participants expressed this through their eagerness to capitalise on new opportunities being presented to them. Yei highlighted this when he said:

If you have a way to go to school why don't you take the chance instead of wasting it, because we have wasted a lot of time there not going to school, a lot of terrible things which we don't want to hear it. We should start thinking and plan our future properly.

\section{Discussion}

Posttraumatic growth outcomes identified by Tedeschi and Calhoun (1996) such as religious changes, relationships with others, strength, appreciation of life, and the compassion dimension identified in the CaucasianAustralian literature (Shakespeare-Finch \& Copping, 2006) were all articulated by this sample. However, these themes were expressed as values that existed prior to the escalation of suffering for Sudanese-Australian participants, rather than as having changed as a result of it. It may be possible that the presence of the cultural values of the Sudanese people means that what we see as posttraumatic growth in the west is in fact a norm for participants in this sample; not discovered post life crisis. Perhaps growth occurs as part of psychosocial development for the Sudanese people and functions as protection from the protracted hardship they have faced, rather than as postcrisis personal development. For example, Janoff-Bulman (1992) suggested that a traumatic event shatters the fundamental assumptions one holds about the self, the world and the place of the self in the world. The first of the assumptions Janoff-Bulman proposes we hold, is that the world is benevolent, that is, good things happen to good people. In a protracted conflict situation such as that which has been present in Sudan for the past 50 years, it may be suggested that the benevolent worldview assumption is in fact absent. Therefore, coping strategies such as strength and religiosity may have developed as a replacement to this assumption.

Hofstede (1984) has suggested that African cultures have high levels of collectivism, unlike the largely individualist western nations such as Australia and the US. That is not to say that there are not collectively oriented individuals in western nations, simply that the broader distal culture promotes notions of individualism and its associated goals. The importance of support in this sample may therefore be a reflection of collectivism in the Sudanese culture. Further, the experiences former refugees have been through are often collectively experienced. That is, all participants in this sample had been through war and suffering in refugee camps. While each person had a different story, the sensation of suffering is a common one for this community, and thus there is no sense that their countrymen do not understand. This is in contrast to the feeling of being misunderstood that has been highlighted in the mainstream Australian culture (Copping et al., 2008).

Often in western mental healthcare, the emphasis is on the individual finding their own way, and the focus is on the individual's expression of their story. In contrast, this sample expressed the need to seek advice from support networks, and the absence of advice provision in Australian services was seen as negligent. The notion of seeking advice is mentioned briefly in Goodman's (2004) study of young Sudanese men's coping strategies; however, it has not been extensively considered as a barrier to accessing mental health services. The difference between the dominant therapeutic paradigm of western psychology and the Sudanese-Australians' expressions of support and seeking advice should be addressed in order to provide culturally appropriate mental healthcare to these clients. 
Effective and culturally competent mental health practice may therefore capitalise on the existing collectivist nature of the Sudanese-Australian culture. Support groups or mentoring schemes may be particularly effective for forced migrants, particularly when involving members of the Sudanese community who have made a successful transition. Social forms of intervention have been particularly effective in refugee populations (Patel et al., 2007; Stepakoff et al., 2006). Story-telling was a theme within the advice-seeking facet that showed potential for integration into western mental health services. Participants felt they were best helped and best able to provide help by sharing stories of similar experiences with each other and gathering advice from these stories.

Christianity is a significant part of life for the Sudanese-Australians in this sample. In addition to their Black African heritage, their religious affiliation was a predominant cause of their persecution in Sudan, and hence those who resettle in Australia often have a very strong Christian faith. It appeared that their belief and faith in Christianity allowed Sudanese-Australian participants to attribute their experiences to the less tangible causes of God and fate. This supports previous research that has also shown religiosity to be a source of strength for Sudanese people (Goodman, 2004; Schweitzer et al., 2007; Shakespeare-Finch \& Wickham, 2009; Tilbury \& Rapley, 2004). Caucasian-Australians, however, tend to focus on control in their post life crisis recovery (Copping et al., 2008). Conversely, experiencing war situations for protracted periods in which control is taken away from a person, along with cultural ideals in which a sense of control is not a dominant value, may lead Sudanese-Australians to more easily hand control over to another source, such as God. This can equally be seen in those for whom Christianity, or other forms of religious or spiritual belief, is a strong part of their explanatory system, regardless of their cultural background (e.g., Heppner et al., 2006; Jaranson et al., 2004; Lo \& Dzokoto, 2005; Miyazaki, Bodenhorn, Zalaquett, \& Ng, 2008).

It is possible that some mental health professionals in Australia may have a cultural bias towards minimising the influence of a client's religious affiliations on their recovery post-trauma. For example, research has shown that religious coping in European nations is perceived as a negative outcome, such that those using religion to make meaning from their experiences are thought to be avoiding the effects of the event (Znoj, 2005). The expressions of lack of control that the SudaneseAustralian sample made were not articulated in a negative tone by the participants, but rather were expressed as a positive coping mechanism. As a cultural bias towards having control over one's life and recovery from trauma is integral to the western mental healthcare system, it is important that Australian mental health professionals acknowledge the significance of religion and fate for Sudanese-Australians, and to work within these value systems.

Strength and new possibilities represent two posttraumatic growth outcomes that are similarly reflected in this sample and support previous research with Sudanese samples (Goodman, 2004; Schweitzer et al., 2007). Previous research from a range of nations (e.g., Australia, China, South Africa) has shown that these outcomes are the most commonly endorsed dimensions of the Posttraumatic Growth Inventory (Copping et al., 2008; Ho et al., 2004; Peltzer, 2000; Shakespeare-Finch \& Copping, 2006; Tedeschi \& Calhoun, 1996). Posttraumatic growth is the result of cognitive restructuring in the aftermath of a traumatic experience; however, participants in this sample were more likely to express their personal strength as being a reason for their survival, rather than a result of their experiences. Similarly, new possibilities in this sample may be a result of their resettlement in Australia, rather than the restructuring of their life narrative.

The personal strength and determination expressed by Sudanese-Australian participants is something to be valued and encouraged. Similarly, the focus on beginning a new life and capitalising on new opportunities in Australia was important to participants in this study. However, many humanitarian entrants have difficulties finding employment and sometimes struggle with education due to differences in educational practices (Boyce \& Madden, 2000; Department of Immigration, Multicultural and Indigenous Affairs [DIMIA], 2003; Flanagan, 2007). This can place greater stress on the individual, particularly given the cultural importance of providing support for family members in Australia and those still living in Africa. Offering assistance to Sudanese-Australians in the area of employment and education would help to relieve some of the distress they face in Australian society and therefore assist in their posttrauma adaptation. For example, in research aimed at understanding helps and hindrances to the resettlement journey, former refugees have consistently recommended positive discrimination in terms of providing assistance and employment opportunities to their communities (Flanagan, 2007; Shakespeare-Finch \& Wickham, 2009).

The current study therefore supports Kagee's (2004; Kagee \& Price, 1994) proposal that mental health practitioners could effectively work within a holistic systems-based approach, providing community development and advocacy, and capitalising on pre-existing strength in these clients in order to ameliorate distress. For example, Silove (1999) argues that five core systems impact on one's trauma adaptation journey: safety/ security, attachment, justice, role/identity and existential/meaning. Each of these systems is equally affected by premigration, en route, and postmigration factors. Therefore, providing therapeutic options that target 
components of each of these systems should focus not only on premigration trauma but also on ongoing resettlement challenges. By utilising existing strengths and coping resources that are grounded in cultural value systems, the mental health practitioner can engage more effectively and appropriately with clients of CALD backgrounds. The development and evaluation of this approach is a viable avenue for future research and would contribute greatly to the provision of culturally appropriate mental health services.

These results offer some valuable information for the mental health community, such as the advice-seeking paradigm found in these data and a focus on religious coping. Mainstream Australians should be encouraged to acknowledge and support the strength, hope and determination of African Australians. Educational and employment opportunities will assist in reducing the distress of postmigration crises, which may then allow the opportunity to more readily address premigration trauma, trauma suffered en route and ongoing difficulties postmigration. It is hoped that, in its development, this research will continue to assist African humanitarian migrants to share their stories, and the mainstream public and professionals to understand how important this is for healing. In this way, we will be able to better support these new Australians.

\section{References}

American Psychiatric Association. (2000). Diagnostic and statistical manual of mental disorders (4th ed.; text rev.). Washington DC: Author.

Blaikie, N. (2000). Designing social research. Cambridge: Polity Press.

Boyce, J., \& Madden, K. (2000). Promoting the development of sustainable refugee communities in Tasmania [Electronic Version]. Social Action Research Centre, Anglicare Tasmania. Retrieved November 20, 2008, from http://www. anglicare-tas.org.au/index.php?option $=$ com_docman \& task=doc_view\&gid $=2 \&$ Itemid $=127$

Calhoun, L., \& Tedeschi, R. (Eds). (2006). Handbook of posttraumatic growth: Research and practice. Hoboken, NJ: Lawrence Erlbaum.

Copping, A., Shakespeare-Finch, J., \& Paton, D. (2008). Modelling the experience of trauma in a White-Australian sample. Proceedings of the 43rd Australian Psychological Society's Annual Conference, 130-135.

Department of Immigration, Multicultural and Indigenous Affairs. (2003). Report of the Review of Settlement Services for Migrants and Humanitarian Entrants. Canberra: Australian Government.

Ethnic Communities' Council of Victoria. (2006). Cultural competence: Guidelines and protocols. Ethnic Communities Council of Victoria. Retrieved June 23, 2008 from http:// www.eccv.org.au

Flanagan, J. (2007). Dropped from the moon: The settlement experiences of refugee communities in Tasmania. Hobart, Australia: Anglicare Tasmania.
Glaser, B., \& Strauss, A. (1967). The discovery of grounded theory: Strategies for qualitative research. Chicago: Aldine.

Goodman, J. (2004). Coping with trauma and hardship among unaccompanied refugee youths from Sudan. Qualitative Health Research, 14(9), 1177-1196.

Halcon, L., Robertson, C., Savik, K., Johnson, D.R., Spring, M., Butcher, J., et al. (2004). Trauma and coping in Somali and Oromo refugee youth. Journal of Adolescent Health, 35, 17-25.

Heppner, P.P., Heppner, M.J., Lee, D.-G., Wang, Y.-W., Park, H.J., \& Wang, L.-F. (2006). Development and validation of a collectivist coping styles inventory. Journal of Counselling Psychology, 53(1), 107-125.

Ho, S.M.Y., Chan, C.L.W., \& Ho, R.T.H. (2004). Posttraumatic growth in Chinese cancer survivors. Psycho-Oncology, 13, 377-389.

Hofstede, G. (1984). Culture's consequences. Thousand Oaks, CA: Sage.

Janoff-Bulman, R. (1992). Shattered assumptions. New York: The Free Press.

Jaranson, J.M., Butcher, J., Halcon, L., Johnson, D.R., Robertson, C., Savik, K., et al. (2004). Somali and Oromo refugees: Correlates of torture. American Journal of Public Health, 94(4), 591-598.

Kagee, A., \& Price, J.L. (1994). Apartheid in South Africa: Toward a model of psychological intervention. International Journal for the Advancement of Counselling, 17, 91-99.

Kagee, A. (2004). Present concerns of survivors of human rights violations in South Africa. Social Science and Medicine, 59, 635-635.

Lo, H.-W., \& Dzokoto, V. (2005). Talking to the master: Intersections of religion, culture, and counseling in Taiwan and Ghana. Journal of Mental Health Counseling, 27(2), 117-128.

McMillen, J. (1999). Better for it: How people benefit from adversity. Social Work, 44(5), 455-468.

Miyazaki, Y., Bodenhorn, N, Zalaquett, C., \& Ng, K.-M. (2008). Factorial structure of Brief COPE for international students attending U.S. colleges. College Student Journal, 42(3), 795-806.

Morris, B., Shakespeare-Finch, J., Rieck, M., \& Newberry, J. (2005). Multidimensional nature of posttraumatic growth in an Australian population. Journal of Traumatic Stress, 18, 575-585.

Murray, K., Davidson, G., \& Schweitzer, R. (2008). Psychological wellbeing of refugees resettling in Australia: A literature review prepared for the Australian Psychological Society. Retrieved November 18, 2008 from http://www.psychology.org.au

National Health and Medical Research Council. (2005). Cultural competency in health: A guide for policy, partnerships and participation. Canberra: Commonwealth of Australia.

Oktikpi, T., \& Aymer, C. (2003). Social work with African refugee children and their families. Child and Family Social Work, 8(3), 213-222.

Patel, V., Araya, R., Chatterjee, S., Chisolm, D., Cohen, A., De Silva, M., et al. (2007). Treatment and prevention of mental 
disorders in low-income and middle-income countries. The Lancet, 370(9591), 991-1005.

Peltzer, K. (2000). Trauma symptom correlates of criminal victimization in an urban community sample, South Africa. Journal of Psychology in Africa, South of the Sahara, the Caribbean and Afro-Latin America, 10, 1, 49-62.

Roncevic-Grzeta, I., Franciskovic, T., Moro, L., \& Kastelan, A. (2001). Depression and torture. Military Medicine, 166(6), 530-533.

Schweitzer, R.D., Greenslade, J., \& Kagee, A. (2007). Coping and resilience in refugees from the Sudan: a narrative account. Australian and New Zealand Journal of Psychiatry, 41(3), 282-288.

Schweitzer, R.D., Melville, F., Steel, Z., \& Lacherez, P. (2006). Trauma, post-migration living difficulties, and social support as predictors of psychological adjustment in resettled Sudanese refugees. Australian and New Zealand Journal of Psychiatry, 40, 179-187.

Shakespeare-Finch, J., \& Copping, A. (2006). A grounded theory approach to understanding cross-cultural differences in posttraumatic growth. Journal of Loss and Trauma, $17,355-371$.

Shakespeare-Finch, J., \& Wickham, K. (2010). Adaptation of Sudanese refugees in an Australian context: Investigating helps and hindrances. International Migration, 48(1), 23-46.

Silove, D. (1999). The psychosocial effects of torture, mass human rights violations, and refugee trauma: Toward an integrated conceptual framework. The Journal of Nervous and Mental Disease, 187(4), 200-207.
Stepakoff, S., Hubbard, J., Katoh, M., Falk, E., Mikulu, J.-B., Nkhoma, P., et al. (2006). Trauma healing in refugee camps in Guinea: A psychosocial program for Liberian and Sierra Leonean survivors of torture and war. American Psychologist, 61, 921-932.

Strauss, A. (1987). Qualitative analysis for social scientists. Cambridge: Cambridge University Press.

Strauss, A., \& Corbin, J. (1998). Basics of qualitative research (2nd ed.). Thousand Oakes, CA: Sage.

Tedeschi, R., \& Calhoun, L. (1995). Trauma and transformation. Thousand Oaks, CA: Sage.

Tedeschi, R., \& Calhoun, L. (1996). The Posttraumatic Growth Inventory: Measuring the positive legacy of trauma. Journal of Traumatic Stress, 9(3), 455-471.

Tedeschi, R., \& Calhoun, L. (2003). Routes to Posttraumatic Growth through cognitive processing. In D. Paton, J. Violanti, \& L. Smith (Eds.), Promoting capabilities to manage postraumatic stress. Chicago, Ill: Thomas Books.

Tedeschi, R., \& Calhoun, L. (2004). Posttraumatic growth: Conceptual foundations and empirical evidence. Psychological Inquiry, 15(1), 1-18.

Tilbury, F., \& Rapley, M. (2004). 'There are orphans in Africa still looking for my hands': African women refugees and the sources of emotional distress. Health Sociology Review, 13(1), 54-64.

Znoj, H. (2005, August). International perspectives on Posttraumatic Growth: PTG from an European perspective. In R. Tedeschi (chair) International Perspectives on Posttraumatic Growth. Symposium conducted at the 113th Annual Convention of the American Psychological Association. Washington DC, US. 